\title{
HIGHLY EFFECTIVE COVERING MATERIALS WITH QUANTUM DOTS FOR GREENHOUSES
}

\author{
Sergei A. Pavlov ${ }^{1}$, Sergei L. Koryakin ${ }^{1,2}$, Natalia E. Sherstenyova ${ }^{1}$, \\ Elena Yu. Maksimova ${ }^{1,3}$, and Eugene M. Antipov ${ }^{1,2}$ \\ ${ }^{1}$ Dmitry Mendeleyev University of Chemical Technology of Russia, Moscow \\ ${ }^{2}$ Lomonosov Moscow State University \\ E-mail:maksimovalkm@yandex.ru
}

\section{ABSTRACT}

The article considers the application of light-converting polymer films as cover materials for the cultivation of greenhouse crops in a covered soil. We analyse the impact of increasing the level of photosynthesis-active radiation (PAR) level in a greenhouse depending on the season, latitude, the angle of the sun, duration of daylight and on other parameters. The article presents some results of growing crops in greenhouse facilities located at the latitude of Moscow region. The results include a significant shorter vegetative stage, as well, as substantial increase in yield from 30 to $100 \%$ in comparison with the reference conditions.

Keywords: quantum dots $C d S e / C d S / Z n S$, emission peak, exciton absorption peak, fluorescence layers, light transformation, photosynthesis, photosynthesis-active radiation, PAR

Most uses of solar energy are partially restricted by the fact that the radiation spectrum is not always radiating energy effectively. The crucial process of photosynthesis also does not always receive the full benefits of the Sun.

Modern agricultural science has identified a fundamental factor limiting photosynthetic efficiency of a green plant as the number of solar radiation quanta available to be absorbed by a green leaf. In the early 1900s K.A. Timiryazev came to the following fundamental conclusion: "We can give a plant any amount of fertilizer and water, we can
\end{abstract}

protect it against the cold in the greenhouses and accelerate carbonic acid circulation, but we will never cultivate more organic substances than the solar energy that is absorbed by the plant. It is a limit which cannot be contravened by mankind. But once we understand this limit, we will obtain a real, strictly scientific measure for the productivity limit of each territory and region, and at the same time we will be able to judge to what extent our cultivation practice approaches perfection..." 1 .

The study of the influence of light spectral composition on plant growth, undertaken in Russia and abroad since the 1950s has identified the impact of various spectral radiation intervals. Multiple experimental data, [1-4] for example, show that leaves absorb a lot of energy in the blue and near ultra-violet spectrum intervals $(350-450) \mathrm{nm}$, and in the red visible interval (600-650) $\mathrm{nm}$. Minimal absorption occurs in the green area $(500-550) \mathrm{nm}$, and at wavelengths greater than $750 \mathrm{~nm}$ there is almost no radiant energy absorption. Some absorption occurs in the near IR interval, which is driven by the water content of the leaves.

The most physiologically important absorption is in the interval of $(600-700) \mathrm{nm}$. Most of this affects the plant chlorophyll, with a small amount also absorbed by some other pigments, for example, in carotenoids. This area of the spectrum is the "photosynthesis-active radiation" (PAR). Typical absorption spectrum of green leaf chlorophyll is

${ }^{1}$ It is quoted according to [19] 


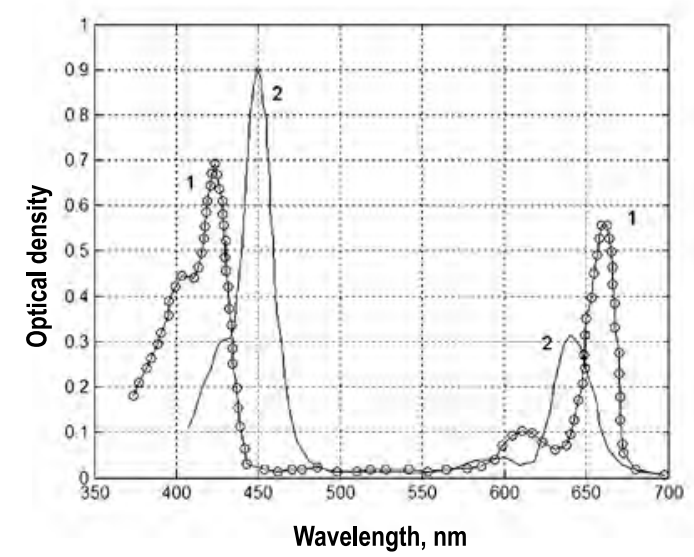

Fig. 1. Absorption spectrum of chlorophyll in the visible area: 1 - chlorophyll $a$; 2 - chlorophyll $b$

shown in Fig. 1. Further, Fig. 2 shows known spectral intensity distributions of direct and scattered solar radiation, and Fig. 3 shows diagrams of relative spectral distribution of photosynthesis efficiency according to McCree [5]. It can be inferred from the presented data that an increase in photosynthesis process efficiency can only happen by adding PAR spectral area radiation [6]. Comparing Figs. 1 and 3 with the solar spectrum given in Fig. 2 shows that maximum value of solar radiation intensity does not coincide either with either the chlorophyll absorption maximum value, or with action spectrum maximum area for photosynthesis. This work will not attempt to uncover the reasons of such evolutionary inefficiencies, which are still a mystery $[4,7]$. The important fact remains that the most valuable radiation from the point of view of biological productivity is located in the red spectrum interval $(600$ 670) $\mathrm{nm}$.

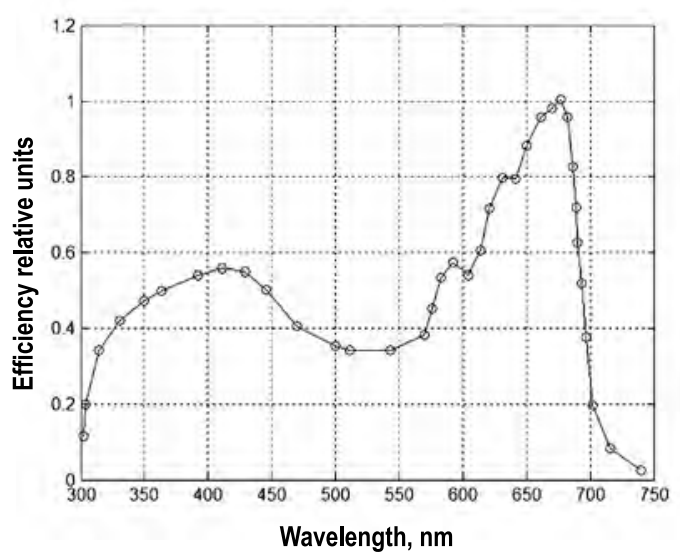

Fig. 3. Relative spectral distribution of radiation photosynthesis efficiency

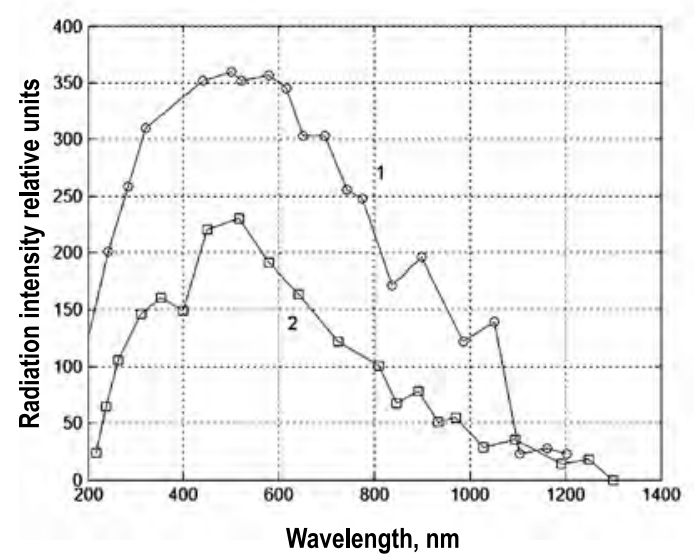

Fig. 2. Relative spectral intensity distributions of direct (1) and scattered (2) solar radiation

In order to correct for the solar spectrum in such a way as to increase its photosynthesis efficiency, we have proposed to use a photoactive additive based on quantum dots of $\mathrm{CdSe} / \mathrm{CdS} / \mathrm{ZnS}$ high pressure polyethylene (HPPE) films as a covering material for greenhouses. These quantum dots are a new generation of phosphors with unique physical and optical properties.

Attempts to use phosphors to correct the solar spectrum were made in the 1980s by some institutes research of the Academy of Sciences of the USSR. In particular, films, containing inorganic and organic photo phosphors based on europium compounds (III), were developed [8]. These phosphors re-emit the ultraviolet component of the sunlight spectrum in the range (300-350) $\mathrm{nm}$ into the red visible part of the spectrum. However, these materials are not widely used in agriculture, due to their suboptimal spectral characteristics: narrow bands

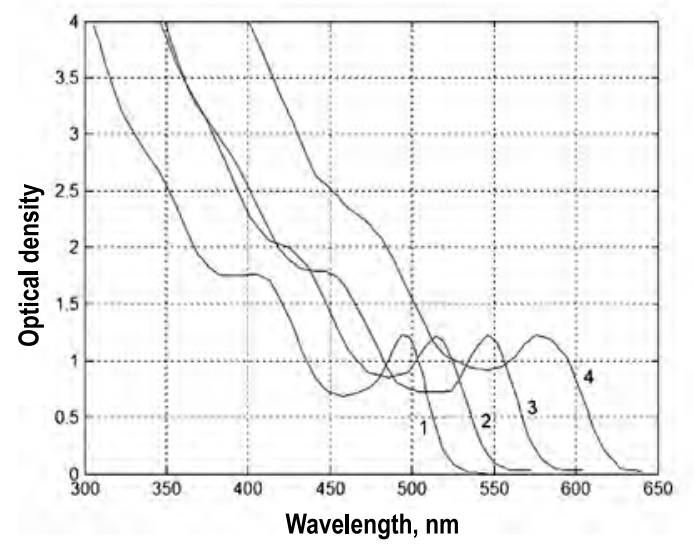

Fig. 4. Typical absorption spectra in the visible spectrum area of polyethylene films containing quantum dots of various size: $1-2.5 \mathrm{~nm} ; 2-2.8 \mathrm{~nm} ; 3-3.4 \mathrm{~nm} ; 4-4.0 \mathrm{~nm}$ 


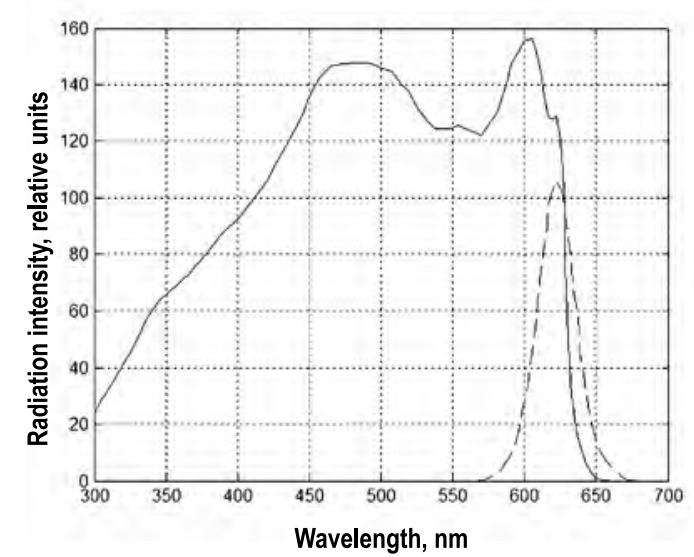

Fig. 5. Excitation spectra (solid line) and radiation spectra (dashed line) of $C d S e / C d S / Z n S$ quantum dots

of absorption and emission, an insufficient value of Stokes shift, a high level of light scattering and low photo stability as well, as a complexity of introducing them into polyethylene matrices.

The creation of a new generation of phosphor based on the $\mathrm{CdSe} / \mathrm{CdS} / \mathrm{ZnS}$ semiconductor colloidal materials has uncovered new possibilities in the development of light transformative materials [9]. Phosphors of this type have some unique optical and colloidal properties, which make them especially attractive for agriculture, because they are materials transforming light. In particular, they are characterised by a wide absorption spectrum in the blue and near ultraviolet regions, Fig. 4, and fluorescence in the form of a relatively narrow peak in practically any range of the visible spectrum.

The general principles of spectral transformation with phosphors were first formulated by S.I. Vavilov. The transformation efficiency is determined by fluorescence energy efficacy, which cannot be greater than 1 . In case of anti-Stokes excitation, i.e. in case $v_{\text {exit }}<\bar{v}$, where $\bar{v}$ is frequency average value in the emission band, photo fluorescence and energy efficacy should decrease with an increase in the frequency difference $\left(\bar{v}-v_{\text {exit }}\right)(10]$. It should be noticed that fluorescence quantum efficacy of the considered materials is close to 1 , which is much useful for practical application.

Along with quantum efficacy, an important factor determining the spectrum transformation efficiency is fluorescence energy efficacy. So, flux $\Phi_{p h}$ radiated by phosphor as a result of its excitation in some wide spectrum interval can be derived by the following expression:

$$
\eta_{\text {en }}=\varphi_{p h}(\lambda) / \varphi_{\text {exit }}(\lambda)
$$

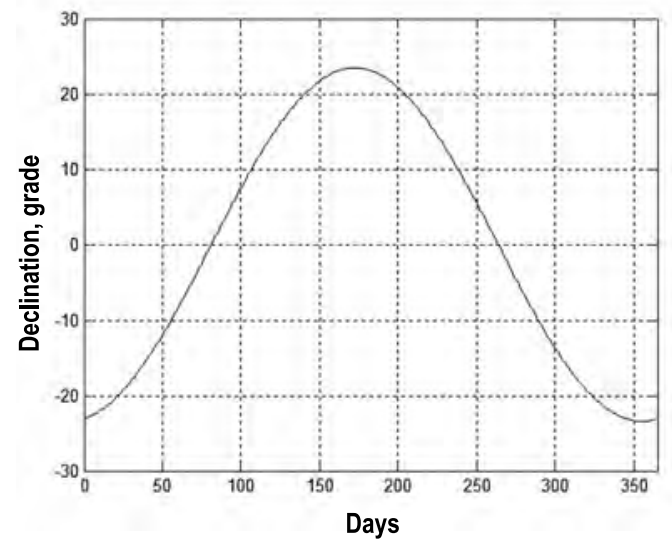

Fig. 6. Sun's declination angle at Moscow latitude $\left(55.7^{\circ} \mathrm{N}\right)$

where $\varphi_{p h}(\lambda)$ and $\varphi_{\text {exit }}(\lambda)$ are correspondent spectral radiation fluxes, $\eta_{e n}$ is fluorescence energy efficacy:

$$
\Phi_{p h}=\int \phi_{p h}(\lambda) d \lambda=\int \phi_{e x i t}(\lambda) \eta_{e n}(\lambda) d \lambda .
$$

The ultimate goal of solar spectrum transformation is the increase of radiation flux in the photosynthesis active radiation (PAR) region [11]:

$$
E_{P A R}=\int_{400}^{700} c(\lambda) I(\lambda) d \lambda
$$

where $c(\lambda)$ is the action spectrum for photosynthesis, $I(\lambda)$ is the spectral distribution of solar radiation strength. Comparing the quantum yield of photosynthesis, Fig. 3, and the spectra of excitation and emission of quantum dots, Fig. 5 clearly indicates the expediency of quantum dots for these purposes.

Under natural illumination conditions, PAR flux depends on a number of factors. First, as shown by the curves in Fig. 2, the spectra of direct and scattered natural radiation are substantially different. Direct radiation strikes the Earth's surface as a collimated flux. Scattered radiation falls on the Earth after its particles are reflected and dispersed by air, water droplets, by ice crystals and atmospheric impurities. Total flux includes both types of radiation, and the ratio of those components depends simultaneously on the state of the atmosphere and on the season, as well on the Sun's altitude above the horizon. For instance, scattered radiation strikes plants before sunrise, but with the increasing height of the Sun, the share of direct radiation increases, and the scattered share decreases. 


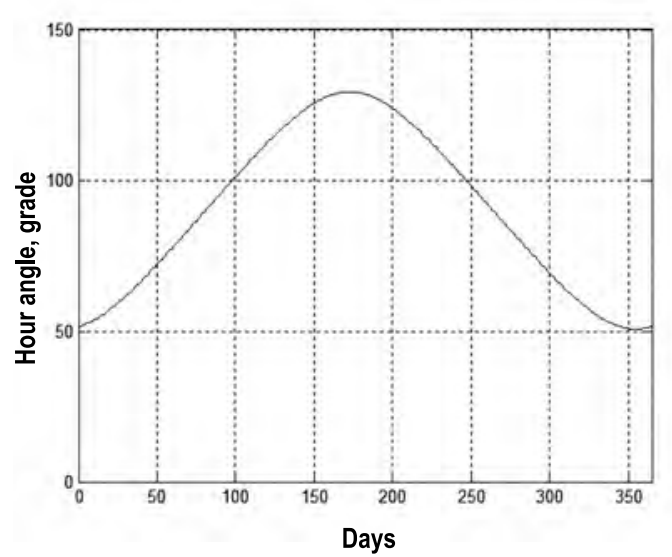

Fig. 7. Annual dependence of hour angle at sunset at Moscow latitude $\left(55.7^{\circ} \mathrm{N}\right)$, days are counted from January 1

Secondly, the efficiency of radiation transformed by a phosphor layer depends on the irradiation conditions mentioned above, namely, on the ray angles incidence, which in their turn depend on the Sun declination, on daylight duration, on the scattered component share of flux and on other parameters. Studying the generic principles of fluorescence in optical layers in detail, which we have previously published in [13-15], determined some factors to be considered when predicting the light transformation process. As the "astronomic" aspects of solar radiation are widely known, we will use them to explain other observed patterns.

Total solar radiation flux (per unit area) falling upon a horizontal plane can be calculated by a formula similar to the one given in [11]:

$$
H_{0}=\left(\frac{t_{s} G_{0}}{\pi}\right)\left(\begin{array}{c}
\cos \phi \cdot \cos \delta \cdot \sin W_{s}+ \\
+\frac{2 \pi W_{s}}{360} \sin \phi \cdot \sin \delta
\end{array}\right),
$$

where $G_{0}$ is the solar constant $\left(G_{0}=1.34 \mathrm{~kW} / \mathrm{m}^{2}\right)$; $\varphi$ is geographic locality latitude; $t_{\mathrm{s}}$ is daylight duration, s; $\delta$ is the Sun declination angle; $W_{\mathrm{s}}$ is hour angle of the Sun at sunset.

Further, declination of the Sun $\delta$ can be determined as

$$
\delta=\delta_{0} \sin [360 \cdot(284+n) / 365],
$$

where $\delta_{0}=23,5^{\circ}, n$ is the number of the day of the year. Duration of daylight in hours can be calculated using the formula:

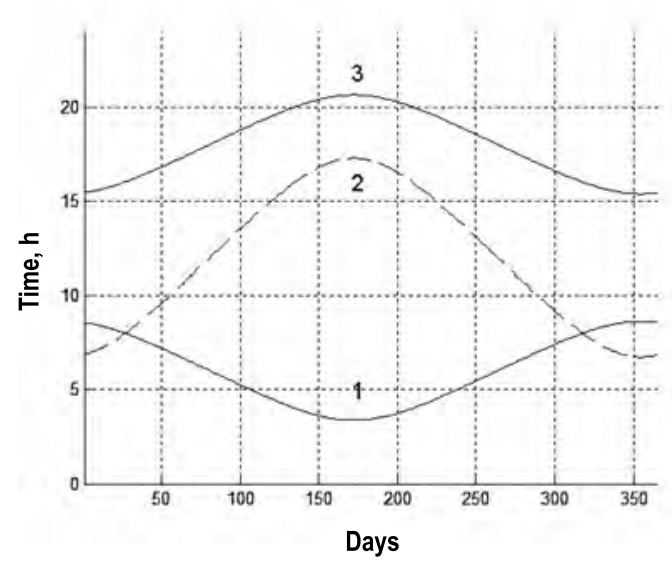

Fig. 8. Results of determining daylight duration, as well as sunrise and sunset time at Moscow latitude of $\left(55.7^{\circ} \mathrm{N}\right)$ by average universal solar time: 1 - duration of daylight; 2 - sunrise time; 3 - sunset time

$$
t_{s}=\frac{2}{15} \arccos (-\tan \phi \tan \delta)
$$

Sunset time (by average universal solar time) is calculated by the formula:

$$
t_{z}=6+\frac{12}{\pi} \arcsin (\tan \phi \tan \delta) .
$$

The results of the calculations according to formulas (5-7) are essential for evaluating the light transformation use efficiency. They are given in Figs. 6-8.

As Earth orbit is not circular but elliptic, ellipticity should be included using the formula [11]:

$$
H=\left[1+e \cdot \cos \left(\frac{360 n}{365}\right)\right] H_{0},
$$

where $e=0.333$ is a constant, which reflects the Earth's orbit ellipticity.

It is considered that solar radiation reaches Earth surface as a sum of direct and scattered fluxes [11]. As direct and scattered fluxes have various spectral compositions, Fig. 2, this influences the efficiency of the light transformation process. Let's evaluate a "clarity index" $k_{T}$, which is a relation of the total daily solar radiation flux incident on the Earth's surface unit area of a horizontal site to the correspondent solar radiation flux outside the atmosphere.

$$
k_{T}(n)=\frac{H_{1}(n)}{H(n)},
$$




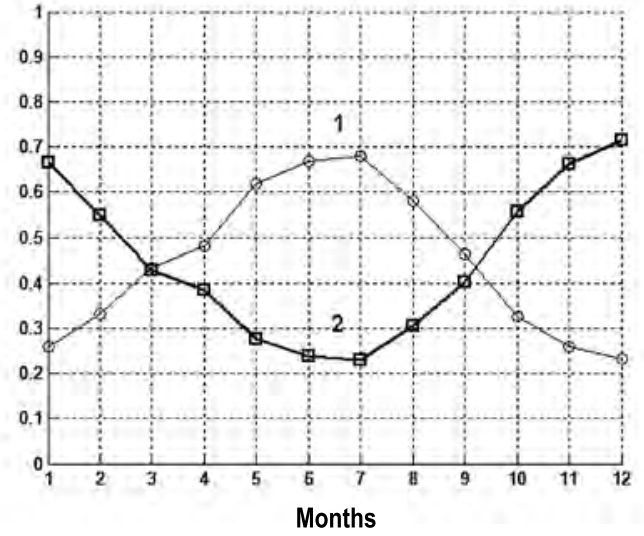

Fig. 9. Time change of clarity coefficient (1) and of scattered flux share (2), relative units

where $H_{1}(n)$ is value of solar radiation flux, which reaches the Earth's surface.

Further, diffuse radiation share $H_{D}$ can be determined using the formula:

$$
\frac{H_{D}}{H_{1}}=1.39-4.03 k_{T}+5.53 k_{T}^{2}-3.11 k_{T}^{3} \text {. }
$$

In essence, the process of solar spectrum transformation constitutes emission (reradiation) at a certain light wavelength absorbed in a wide spectral interval. Examples of absorption spectra for the materials, which we have developed based on HPPE containing quantum dots of various dimensions, are given in Fig. 4. A unique feature of the quantum dot

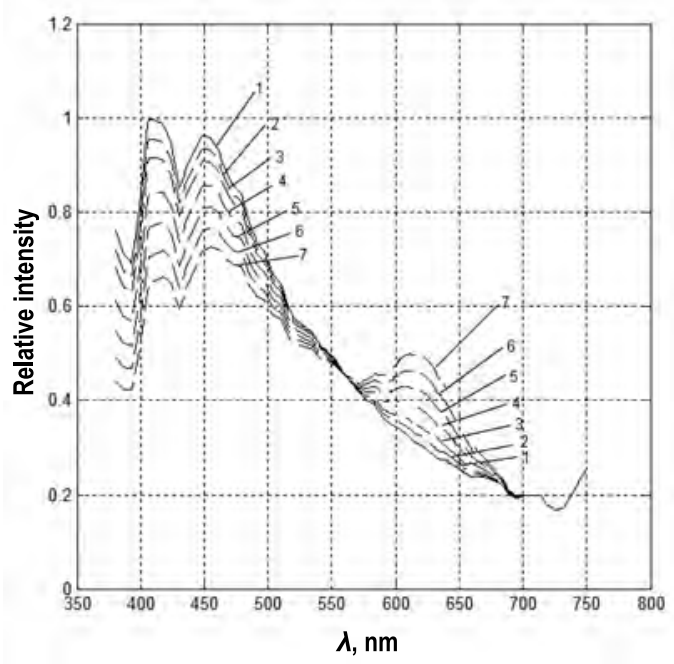

Fig. 11. Natural irradiance spectrum under HPPE film (50 $\mu$ thickness) containing various concentrations of a photoactive component: 1 - unmodified film, 2 - contains $0.1 \mathrm{mg} / \mathrm{g}$ of quantum dots, $3-0.2 \mathrm{mg} / \mathrm{g}, 3-0.4 \mathrm{mg} / \mathrm{g}, 5-0.6$ $\mathrm{mg} / \mathrm{g}, 6-0.8 \mathrm{mg} / \mathrm{g}, 7-1.0 \mathrm{mg} / \mathrm{g}$

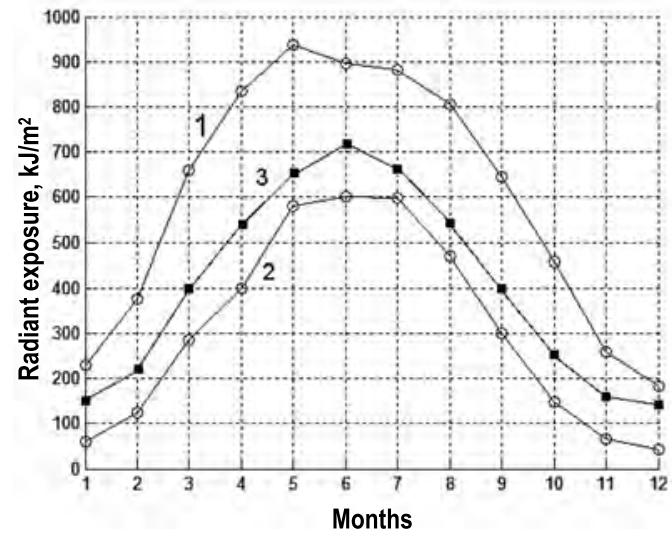

Fig. 10. Total exposure of solar radiation (1), exposure of scattered radiation (2), and total exposure of the transformed radiation in the PAR interval (3)

optics is a wide, almost continuous absorption spectrum in the blue and near ultra-violet ranges in an interval of wavelength lesser than the excitonic absorption peak. This is non-typical for traditional ceramic and organic phosphors, including rare-earths. Another feature of the developed materials is a dependence of spectrum transformation efficiency on the collimated solar radiation angle when passing through the fluorescence layer. This is caused both by a change of the physical properties of light (in particular, its spectral composition), and by the efficiency of the light transformation process itself by the layer with change of incidence angle $h$. Problems of light transformation efficiency connected with changing light ray angle when passing through the layer have been previously considered [13].

Further, incidence angle of collimated solar radiation is determined by a known formula [16]

$$
\sin (h)=\sin (\phi) \sin (\delta)+\cos (\phi) \cos (\delta) \cos (t) .
$$

The incidence angle of collimated solar radiation flux at Moscow latitude at noon is given in Fig. 6. Determination of the collimated and scattered fluxes ratio was carried out formerly based on the triple-flux approximation [16]. PAR increase is estimated depending on natural illumination conditions. A calculation of full PAR flux (or dose) was carried out using the formula:

$$
\sum Q_{D A P}=A \sum S+B \sum D+\Phi_{p h},
$$

where $A=0.6$, B is transition coefficient from daytime sums of direct solar radiation to the day-time sums of direct PAR (Table 1); $\sum S$ is full flux of 
Table 1. Effective transition coefficients from day sums of direct solar radiation to day sums of direct PAR for various latitudes [18]

\begin{tabular}{|c|c|c|c|c|c|c|c|c|}
\hline \multirow{2}{*}{ Locality latitude, grade } & \multicolumn{9}{|c|}{ Month } \\
\cline { 2 - 10 } & $\mathbf{5}$ & $\mathbf{6}$ & $\mathbf{7}$ & $\mathbf{8}$ & $\mathbf{9}$ & $\mathbf{1 0}$ & $\mathbf{1 1}$ & $\mathbf{1 2}$ \\
\hline 66 & 0.40 & 0.40 & 0.40 & 0.39 & 0.37 & & & \\
\hline 50 & 0.41 & 0.42 & 0.42 & 0.41 & 0.405 & 0.385 & & \\
\hline 23 & 0.425 & 0.425 & 0.425 & 0.425 & 0.420 & 0.415 & 0.410 & 0.41 \\
\hline
\end{tabular}

scattered radiation, $\sum D$ is full flux of direct radia-

tion, $\Phi_{p h}$ is fluorescent flux.

Calculation results are given in Figs. 9, 10. Seasonal changes of clarity coefficient and of the share of scattered radiation are given in Fig. 9. Further, the experimental irradiance spectra obtained for a photoactive component based on quantum dots $\mathrm{CdSe} / \mathrm{CdS} / \mathrm{ZnS}$, Fig. 11, using formula (12), the contribution of fluorescent flux $\Phi_{p h}$ to PAR was determined (Fig. 10, curve 3 ). It is seen that in the $(600$ $650) \mathrm{nm}$ PAR interval, radiation intensity increases by (15-65)\% depending on the test time.

Experimentally, at first approximation, the efficiency of light transformation $(\chi)$ can be estimated by changes of integral intensity in the (400-550) nm and of (550-700) $\mathrm{nm}$ spectral range:

$$
\chi=\int_{400}^{550} I(\lambda) d \lambda / \int_{550}^{700} I(\lambda) d \lambda .
$$

Processing the experimental data given in Fig. 10 showed that $60 \%$ of the radiation absorbed in the blue area is fluoresced in the red area. Radiation losses are no greater than $40 \%$. In order to correct the fluorescence spectrum, we also used mixtures of quantum dots dispersion with various maximum emission values. We have previously studied effective spectra of such mixtures in $[14,15]$.

It should be noticed that at Russia's midlatitudes, yield capacity is almost proportional to the meteorologically possible PAR flux [17-20]. Therefore, when increasing PAR flux by $50 \%$, a proportionate increase in photosynthetic intensity can be expected. This is illustrated by the spectrum under an HPPE film (50 $\mu$ thickness) containing various concentrations of a photoactive component (Fig 11). The figure shows a significant increase in radiation intensity in the PAR interval.
We have carried out tests of the developed material based on a HPPE film containing quantum dots at the same latitudes as Moscow region [21]. The following cultures were tested in protected soil: white cabbage (Brassica oleracia var. capitata L.), cauliflower (Brassica oleracia var. botrytis L.), lettuce (Latuca sativa L.), tomatoes (Salanum lycopersicum erensuletum), and cucumbers ( $\mathrm{Cu}$ cumis sativus). The results completely confirmed the assumptions.

The biomass of the Brassica oleracia var. capitata $L$. cabbage grown under the light transforming film, was (45-75)\% higher than under the reference conditions (a non-fluorescence film). Biomass increase of the Brassica oleracia var. botrytis L. cabbage and of the Latuca sativa $L$ lettuce was up by $(30-40) \%$ and $(25-30) \%$ respectively. Weight of the Salanum lycopersicum erensuletum tomato fruits and of the Cucumis sativus cucumber increased up to $35 \%$ and $50 \%$ respectively.

Some results of growing cucumbers of the Prestige and Miracle brands in protected ground under fluorescent films are given in Table 2. The yield increase in these experiments is significantly higher than the experiment statistical error. The results for the production capacity of the La-La-Fa brand of tomato $\left(F_{1}\right.$ hybrid) are given in Table 3 . It can be seen that production capacity depends on quantum dots concentration in the covering material, and that maximum productivity corresponds to the material quantum dots concentration of (3-5) $\mathrm{mg} / \mathrm{g}$.

\section{CONCLUSIONS}

1. Studying the optical properties of polymer films containing quantum dots as a photoactive component led to identifying the main features of the solar spectrum transformation process. It was found out that solar spectrum transformation efficiency depends both on fluorescent and optical film 
Table 2. Cucumbers Yields (Prestige and Miracle brands) at 90 days of Age, Grown in Protected Ground Under the Developed Fluorescing Films

\begin{tabular}{|c|l|c|c|c|}
\hline Brand & \multicolumn{1}{|c|}{ Experiment series } & Yield, $\mathbf{~ k g / \mathbf { m } ^ { 2 }}$ & $\begin{array}{c}\text { Number of fruits, } \\
\text { piece } / \mathbf{m}^{\mathbf{2}}\end{array}$ & Average fruit weight, $\mathbf{g}$ \\
\hline \multirow{2}{*}{ Prestige } & Reference & 6.2 & 65 & 95 \\
\cline { 2 - 5 } & Light transforming film, $2 \mathrm{mg} / \mathrm{g} *$ & 21.0 & 140 & 150 \\
\hline \multirow{2}{*}{ Miracle } & Reference & 13.2 & 110 & 120 \\
\cline { 2 - 5 } & Light transforming film, $2 \mathrm{mg} / \mathrm{g} *$ & 20.8 & 160 & 130 \\
\hline
\end{tabular}

* Concentration of the photoactive component

Table 3. Results of Studying Yield of the La - la - fa Brand Tomato ( $F_{1}$ hybrid) Cultivated in Protected Ground Under a Light Transforming Film Containing Quantum Points in Various Concentrations

\begin{tabular}{|l|c|c|c|c|c|}
\hline \multirow{2}{*}{ Coating } & \multicolumn{3}{|c|}{ Concentration of a photoactive component in the film, mg/g } \\
\cline { 2 - 6 } & $\mathbf{2 . 0}$ & $\mathbf{3 . 0}$ & $\mathbf{5 . 0}$ & $\mathbf{8 . 0}$ & $\mathbf{1 0 . 0}$ \\
\hline Yield, $\mathrm{kg} / \mathrm{m}^{2}$ & 9.1 & 11.7 & 11.5 & 9.3 & 7.7 \\
\hline $\begin{array}{l}\text { Yield increase, \% in comparison with reference } \\
\text { conditions }\end{array}$ & 136 & 150 & 148 & 136 & 124 \\
\hline
\end{tabular}

properties, and on some meteorological and astronomic factors. In particular, on latitude, the Sun declination, daylight duration, shares of direct and scattered solar flux.

2. The dependence of fluorescence flux on the Sun declination angle is mainly connected with the factor of radiation reflection from the geometric surface of angular dependence of the layer transforming light and to a lesser extent, on the scattered flux share in total flux of incident solar radiation.

3. It is found out that the additional impact of fluorescent flux to the natural PAR flux at Russia midland latitudes increases during autumn and winter seasons and decreases during the summer months. Similarly, the efficiency of light transformation increases with latitude. This allows to draw the conclusion that the use of light transforming materials in order to intensify the photosynthesis process is very effective for the midland region of Russia, where there is an obvious PAR, practically during the vegetative stage of crops. Therefore, the use of light transforming materials is expedient both during the basic (summer) harvest period, and during the autumn and winter periods.

4. The efficiency of light transformation can reach $50 \%$. There is very little loss (no more than $40 \%$ ) of radiant flux from absorption by the film in the blue and near ultraviolet regions of the spectrum, and it is of little value for photosynthesis.

5. Preliminary cultivation experiments made with some greenhouse cultures showed a significant increase both of the general biomass, and in the fruit mass caused by the general intensification of photosynthesis as a result of PAR flux increase.

6. The optimum concentration of quantum dots in the covering material is estimated to be between 3 and $5 \mathrm{mg} / \mathrm{g}$.

\section{ACKNOWLEDGEMENT}

The work was performed with financial support from the Ministry of Education and Science of the Russian Federation, Agreement on granting a subsidy \#14.574.21.0064 (unique identifier of the applied scientific research (of the project) is RFMEFI57414X0064).

\section{REFERENCES}

1. Tikhomirov A.A., Sharupich V.P., Lisovsky G.M. Photoculture of plants: biophysical and biochemical fundamentals. Novosibirsk: The publishing house of the Siberian Branch of the Russian Academy of Science, 2000, $213 \mathrm{p}$. 
2. Shpolsky E.V. Absorption spectrum of chlorophyll in a solution and in natural state // Bulletin of the Academy of Sciences of the USSR. Biology series, 1947, \#3, pp. 391-406.

3. Sventitsky I.I. Evaluation of photosynthesis efficiency of optical radiation // Svetotekhnika, 1965, \#4, pp. 19-24.

4. Tikhomirov A.A., Lisovsky G.M., Sidko F. Ya. Spectral light composition and producing capacity of plants// Novosibirsk: Nauka, 1991.

5. McCree, K.J. The Action Spectrum, Absorptance and Quantum Yield of Photosynthesis in Crop Plants // Agricultural and Forest Meteorology, 1972, Vol. 9, pp. 191-216.

6. Molchanov A.G., Samoylenko V.V. Energy saving optical irradiation of industrial greenhouses// Stavropol: ARGUS, 2013, 120 p.

7. Shulgin I.A. A plant and the Sun// Leningrad: Gidrometeoizdat, 1973.

8. Ivanitsky A.E., Koval E.O., Rayda V.S. Fluorescent properties of polyethylene films with photophosphor additives // Fluorescence and accompanying phenomena. Transactions of the $\mathrm{VII}^{\text {th }}$ All-Russian workshop, November 13-18, 2001, Irkutsk, 2002.

9. Vasilyev R.B., Dirin D.N. Quantum dots: synthesis, properties, application. Moscow: FNM, 2007.

10. Adirovich E.M. Fluorescence and laws of spectrum transformation // Achievements of physical sciences// 1950, V. 4, \#3, pp. 341-368.

11. Kondratyev K. Ya. Actinometry// Leningrad.: The hydrometeorological publishing house, 1965, $685 \mathrm{p}$.

12. Pavlov S.A., Maksimova E. Yu., Koryakin S.L., Sherstneva N.E., Antipov E.M. An evaluation of subpixel luminosity of a fluorescent video monitor based on quantum dots of $\mathrm{CdSe} / \mathrm{CdS} / \mathrm{ZnS} / /$ Russian nanotechnologies, 2016, V. 11, \#3-4, pp. 64-68.

13. Pavlov S.A., Krikushenko V.V., Antipov E.M., Voronets N.B. Maksimova E. Yu., Shersneva N.V., Koryakin S.L. Luminuos efficacy and efficiency of fluorescence of polymeric layers containing colloidal semiconductor phosphors based on quantum dots of CdSe/ CdS/ZnS // Optics and spectroscopy. 2015. V. 119, \#2, pp. 133-137.

14. Antipov E.M., Koryakin S.L., Maksimova E. Yu., Pavlov S.A., Sherstneva N.E. Formation features of radiation chromaticity of $\mathrm{CdSe} / \mathrm{CdS} /$ $\mathrm{ZnS}$ quantum dots dispersions in multicomponent systems // Svetotekhnika, 2017, \#4, pp. 31-34.

15. Antipov, E.M., Sergey L. Koryakin, S.L., Elena Yu. Maksimova, E.Y., Sergey A. Pavlov, S.A., Natalya E. Sherestnyova, N.E. Features of Forming CdSe/ CdS/ZnS Quantum Points Dispersion Radiation Chromaticity in Multicomponent Systems // Light \& Engineering, 2017, Vol. 25, No. 3, pp. 244-249.

16. Sivkov S.I. Calculation methods of solar radiation characteristics// Leningrad: The hydrometeorological publishing house, 1968, $232 \mathrm{p}$.

17. Tooming H.G. Solar radiation and harvest formation - Leningrad: Gidrometeoizdat, 1977, 200 p.

18. Tooming H., Niylisk H. Transition coefficients from integral radiation to PAR under natural conditions // In: Photoactinometric studies of plant cover. Tallinn: Valgus, 1967, pp. 140-149.

19. Shain S.S., et. al. Light and plant development. Moscow: Selkhozizdat, 1963, $622 \mathrm{p}$.

20. Leman V.M. A course of plant photoculture. Moscow: Vysshaya Shkola, 1976, $271 \mathrm{p}$.

21. Pavlov S.A., Voronets N.B. Quantum points and harvest // ESU. Chemical sciences, 2014, \#10, pp. 89-91.

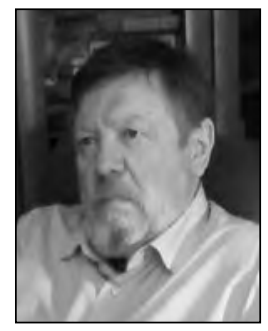

\section{Sergei A. Pavlov,}

Prof., Dr. of Chemical Sc., graduated from Russian University of Chemical Technology named after D.I. Mendeleyev. At present, he is Chief Specialist at the Department of Chemical Technology of Polymer Composite Paints and Coatings, and his field of interests are rheology of macromolecular compounds, colloidal phosphors (quantum dots) in polymer's composite coverings, materials for optical information output devices 


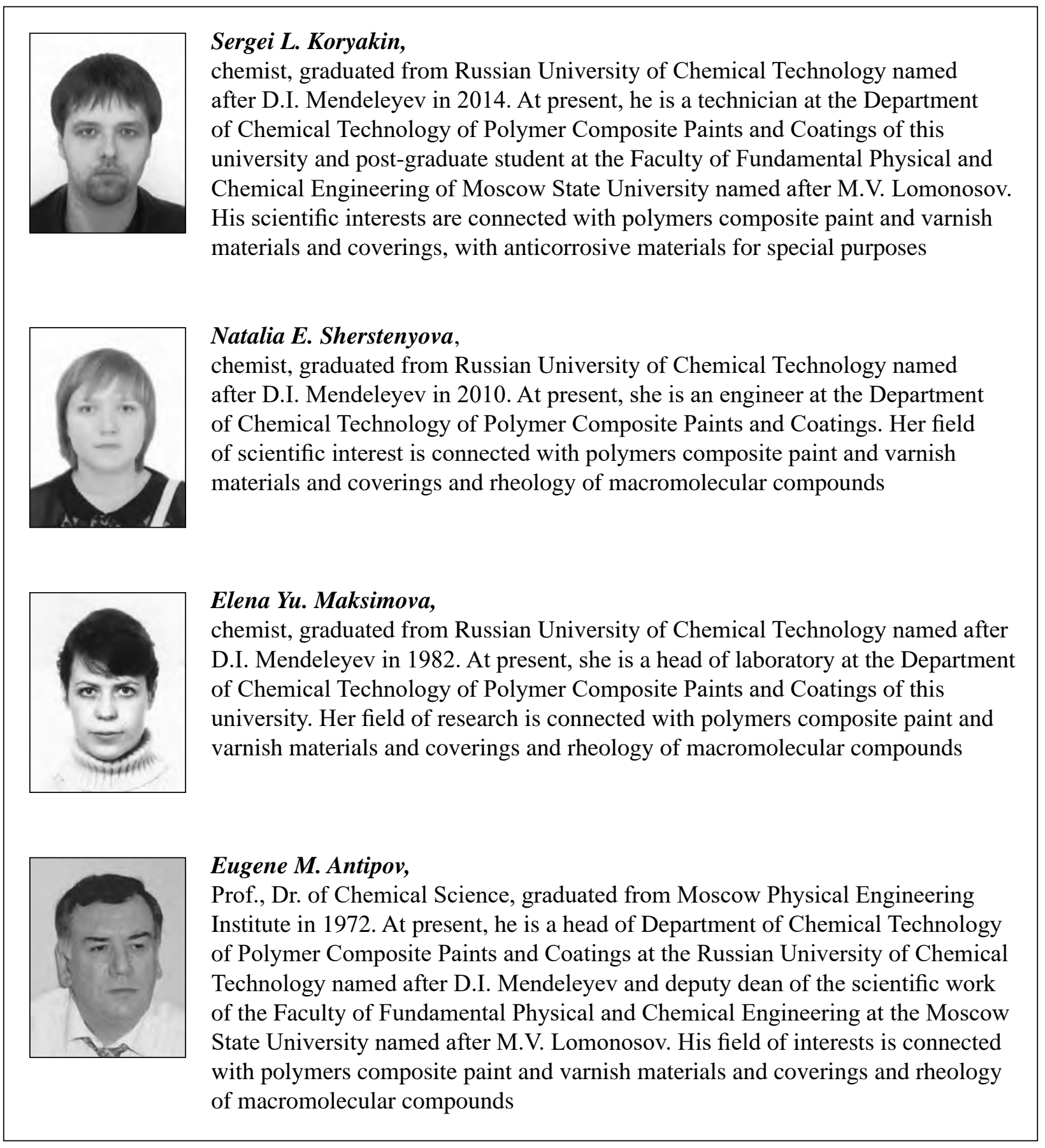

